\title{
Individualizing medical treatment for tobacco dependence
}

\author{
D.P.L. Sachs*, N.L. Benowitz**
}

Tobacco (nicotine) dependence is the chief preventable cause of respiratory disease. In many ways, nicotine dependence is a chronic medical illness, producing long-lasting structural and functional changes in the central nervous system. Tobacco dependence can be treated, but relapses to smoking are common. The responsibility of physicians to treat tobacco dependence is clear, just as it is to treat chronic obstructive lung disease (one major consequence of smoking). The main pharmacological therapy for tobacco dependence is nicotine replacement medication. However, an unresolved question is how best to use, and, in particular, how to individualize nicotine replacement therapy.

In this issue of the European Respiratory Journal, PAOLETTI et al. [1] provide a significant insight towards optimizing the pharmacotherapy of tobacco addiction. Their study is the first nicotine patch trial to prospectively stratify smokers based on a measure of nicotine dependence, in this case the serum cotinine level. They define lowdependent smokers as those with a pretreatment serum cotinine level of $\leq 250 \mathrm{ng} \cdot \mathrm{mL}^{-1}$, and high-dependent smokers as those with serum cotinine levels $>250 \mathrm{ng} \cdot \mathrm{mL}^{-1}$ measured whilst smoking cigarettes during the baseline evaluation period. Based on their nicotine dependency level, subjects were randomly assigned in double-blind fashion, to receive one of two doses of nicotine patch: low-dependent smokers received active standard dose (15 $\mathrm{mg}$ nicotine $\left.\cdot 16 \mathrm{~h}^{-1}\right)$ vs placebo $\left(0 \mathrm{mg}\right.$ nicotine $\left.\cdot 16 \mathrm{~h}^{-1}\right)$; high-dependent smokers received the standard dose (15 $\left.\mathrm{mg} \cdot 16 \mathrm{~h}^{-1}\right)$ vs a higher dose (25 mg nicotine $\left.16 \mathrm{~h}^{-1}\right)$.

The data of PAOLETTI et al. [1] clearly and unequivocally show that low-dependent cigarette smokers are substantially more successful in quitting smoking with an 18 week active nicotine patch treatment period, using the standard dosing (15 mg nicotine $\left.\cdot 16 \mathrm{~h}^{-1}\right)$ compared to placebo. The continuous, one year differential in treatment success was threefold. This result is all the more remarkable, and attests to the importance of nicotine replacement therapy for low-dependent smokers, since no behavioural intervention was provided. These results confirm, prospectively, what SACHS and co-workers [2] reported previously in a retrospective analysis of a nicotine patch trial: low-dependent smokers (defined on the basis of the Fagerstrom Tolerance Questionnaire, (FTQ)) have a substantially better treatment outcome, both while

* Palo Alto Center for Pulmonary Disease Prevention, Palo Alto, CA, USA and Division of Pulmonary and Critical Care Medicare, Stanford University School of Medicine, Stamford, CA, USA and **The Division of Clinical Pharmacology, Department of Medicine, University of California, San Francisco, CA, USA. Reprint requests to: Dr D.P.L. Sachs, 285 Hamilton Ave, Suite 420, Palo Alto, CA 94301-2540, USA. receiving medication and after tapering off medication, than those who are not provided nicotine patch therapy.

PAOLETTi et al. [1] also clearly showed that high-dependent smokers have a low likelihood of success, similar to that of the low-dependent smokers treated with placebo, with no difference in response comparing the two nicotine patch doses. This finding is similar to that first observed retrospectively in the study by SACHS and coworkers [2], which included a placebo patch treatment arm for the high-dependent smokers.

What does the low success rate in high-dependent smokers after treatment with either 15 or $25 \mathrm{mg}$ of nicotine, delivered via transdermal patch over $16 \mathrm{~h}$, mean? We suggest three interpretations: 1) even a dose of 25 $\mathrm{mg}$ nicotine $\cdot 16 \mathrm{~h}^{-1}$ is still far too low for high-dependent smokers; 2) the percentage cotinine replacement level needed is not absolute, e.g. 50, 75 or $100 \%$, but is rather, as Paoletti et al. [1] suggest, a function of the level of dependence; in other words, the higher the smoker's dependence on entering treatment, the higher the degree of cotinine replacement needed to establish effective nicotine replacement therapy; and 3) nicotine patches are simply an ineffective nicotine delivery system for high-dependent smokers. This could be because the rate of absorption of nicotine into the blood stream, and thus into the central nervous system, from the patch is simply too slow to satisfy the high-dependent smoker's nicotine needs; and that a medication with a different pharmacokinetic absorption profile, such as nicotine polacrilex, $4 \mathrm{mg}$, or nicotine nasal spray, is needed.

SACHS [3] has shown, in a prospective, double-blind, dose-response, placebo-controlled trial that high-dependent smokers (defined as FTQ $\geq 7+$ baseline serum cotinine level $>250 \mathrm{ng}$ cotinine $\cdot \mathrm{mL}^{-1}$ blood + baseline exhaled carbon monoxide level $>15$ parts per $(\mathrm{ppm})$ ) did substantially better at the end of the 6 week treatment period with the $4 \mathrm{mg}$ dosage of nicotine polacrilex than with either the $2 \mathrm{mg}$ or the placebo dosages. In fact, the continuous abstinence rates, using the same criteria as PAOLETTI

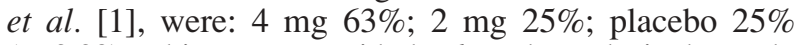
$(\mathrm{p}<0.02)$. This contrasts with the 6 week results in the study by PAOLETTI et al. [1] for high-dependent smokers treated with either 15 or $25 \mathrm{mg}$ of transdermal nicotine.day ${ }^{-1}$ of approximately $15 \%$. Thus, the active nicotine patch results for the high-dependent smokers of PAOLETTI et al. [1] were no better than the placebo nicotine polacrilex treatment results of SACHS [3]. Also of note, SuTHERLAND et al. [4] have reported a post hoc analysis that suggested that nicotine nasal spray provides a preferential advantage to high-dependent smokers, defined based on baseline plasma nicotine concentrations.

The findings of PAOLETTI et al. [1] in this issue of the 
Journal are important for another reason. There are relatively few trials with either transdermal nicotine or nicotine polacrilex which have attempted, in randomized, double-blind, controlled fashion, to objectively assess the difference that nicotine replacement therapy might have for high- or low-dependent smokers. Five such studies have been reported, three with nicotine polacrilex $[3,5$, $6]$ and two with transdermal nicotine, including that reported in this volume $[1,2]$. Four of the studies looked at low-dependent smokers and showed the same result: improved, continuous smoking cessation both initially and at 1 year follow-up 3-10 fold better with nicotine replacement therapy than placebo $[1,2,5,6]$. All three nicotine polacrilex studies showed that high-dependent smokers were effectively treated (twofold or better improvement compared to placebo) with $4 \mathrm{mg}$ nicotine polacrilex $[3,5,6]$. Both nicotine patch studies showed that standard, or even higher, doses of transdermal nicotine were minimally effective for high-dependent smokers [1, $2]$. One caveat should be noted, SACHS and co-workers [2] found that high-dependent smokers showed a twofold increase in continuous abstinence, compared to placebo patch-wearers, while they were still receiving medication, but that relapse was immediate and substantial after they went off active patch therapy (double-blind still being maintained). Thus, patch therapy may have initial efficacy for high-dependent smokers which, with current, short-term treatment schedules (4 weeks to 3 months), is lost prior to assessment of long-term outcome.

Apart from the issue of differential therapeutic needs for high-dependent smokers $v s$ low-dependent smokers, there is the general issue of dose-response relationship. The investigation by PAOLETTI et al. [1] is one of the few to attempt to tackle both in one study. There are three other dose-response nicotine patch studies in the literature [7-9], although one of these had no placebo condition [7]. The first dose-response nicotine patch study showed a clear-cut, highly significant dose-response relationship at the end of 6 weeks of treatment, with those assigned to placebo patch achieving $33 \%$ continuous abstinence rate compared with $71 \%$ for those assigned to receive $21 \mathrm{mg}$ nicotine $24 \mathrm{~h}^{-1}[8,10]$. This study, however, included smokers of all dependency ranges, and did not present any pre- or post hoc analysis for highor low-dependent smokers.

The recently published study by JORENBY et al. [7] was much more complex. It involved randomly assigning smokers to one of two nicotine patch doses, 22 or 44 $\mathrm{mg} \cdot 24 \mathrm{~h}^{-1}$, and to one of three behavioural interventions: minimal counselling, individual counselling, or group counselling. They did find a dose-response relationship for those subjects assigned to the minimal counselling condition (68 vs 45\%, for the 44 vs $22 \mathrm{mg}$ dosages, at the end of the 4-week double-blind treatment period). They did not find a dose-response effect when behavioural intervention was more intense. Subjects were not stratified in this trial, however, either by sex or any measure of nicotine dependence. As with the Transdermal Nicotine Study group trial, no pre- or post hoc analyses was presented for high- or low-dependent smokers [7]. Also, cotinine blood levels were not measured in either of these two studies during nicotine patch treatment in order to enable computation of the percentage cotinine replacement actually achieved. Thus, it is impossible to analyse the results from these two studies fully, in light of the findings of the current study by PAOLETTI et al. [1].

The third published nicotine patch, dose-response trial reported by DALE et al. [9] did measure serum cotinine and nicotine levels during nicotine patch treatment and was able to analyse outcome results as a function of cotinine replacement achieved by treatment. This study showed that the higher the percentage cotinine replacement by nicotine patch dose, the better the 8 week smoking cessation rate.

There is, yet, a fourth "dose-response" trial, which we have recently reported at a national meeting in the United States [11]. In this study, we reasoned that since both transdermal absorption and subsequent metabolism of the nicotine are highly variable from subject to subject, it made more sense to focus on resultant blood nicotine (or cotinine) replacement level, rather than dose. Consequently, the trial subjects, stratified both by sex and nicotine dependence, were assigned prospectively to receive a sufficient nicotine patch dose to attain either 0,50 or $100 \%$ cotinine replacement from nicotine patch therapy, in relation to their cotinine levels during baseline cigarette smoking. We found a clear-cut, highly significant improvement in smoking cessation rates, the higher the cotinine replacement achieved by nicotine patch therapy.

In a recent editorial, HugHes [12] concluded that there is insufficient evidence to use higher than standard doses of transdermal nicotine in smoking cessation therapy. We disagree. Based on our own study [11], as well as that of PAoletti et al. [1] and Dale et al. [9], we see a definite dose-response relationship for transdermal nicotine therapy, as is seen with many other drugs, such as theophylline related to improvement in ventilatory function.

Our review of the literature and the current study of PAOLETTI et al. [1] lead us to the following clinical recommendations for optimal use of nicotine replacement therapy:

1. Serum cotinine levels should be routinely determined by the physician while the patient is still at regular, baseline smoking rates before beginning treatment of tobacco dependence.

2 . If serum cotinine whilst smoking is $\leq 250 \mathrm{ng} \cdot \mathrm{mL}^{-1}$, then such low-dependent smokers can be effectively treated with current, standard nicotine patch dosing (15-25 mg nicotine $\cdot$ day $\left.^{-1}\right)$.

3. If serum cotinine is $>250 \mathrm{ng} \cdot \mathrm{mL}^{-1}$ blood, then nicotine patch, in existing, standard doses of $15-25 \mathrm{mg}$ nicotine $\cdot$ day $^{-1}$, is not the treatment of choice, since clinical trials have shown such treatment to be ineffective.

4. Such high-dependent smokers should instead be prescribed nicotine polacrilex, $4 \mathrm{mg}$ dosage, 12 pieces.day-1 or nicotine nasal spray, since such treatment is effective.

A question which remains to be answered is whether achieving higher percentage cotinine replacement levels from nicotine patch therapy can further improve outcome results for low- or high-dependent smokers; we think this to be likely. Studies now in progress should shed substantial light on this critical question.

\section{References}

1. Paoletti P, Fornai E, Maggiorelli F, et al. Importance of baseline cotinine plasma values in smoking cessation: 
results from a double-blind study with nicotine patch. Eur Respir J 1996; 9: 643-651.

2. Sachs DPL, Sawe U, Leischow SJ. Effectiveness of a 16 hour transdermal nicotine patch in a medical practice setting, without intensive group counselling. Arch Intern Med 1993; 153: 1881-1890.

3. Sachs DPL. Effectiveness of the $4 \mathrm{mg}$ dose of nicotine polacrilex for the initial treatment of high-dependent smokers. Arch Intern Med 1995; 155: 1973-1980.

4. Sutherland G, Stapleton JA, Russell MAH, et al. Randomised controlled trial of nasal nicotine spray in smoking cessation. Lancet 1992; 340: 324-329.

5. Tonnesen P, Fryd V, Hansen M, et al. Effect of nicotine chewing gum in combination with group counseling on the prevention of smoking. N Engl J Med 1988; 318: $15-18$.

6. Herrera N, Franco R, Herrera L, Partidas A, Rolando R, Fagerstrom KO. A double-blind, placebo-controlled trial within a behavior modification support program. Chest 1995; 108: 447-451.

7. Jorenby DE, Smith SS, Fiore MC, et al. Varying nico- tine patch dose and type of smoking cessation counseling. JAMA 1995; 274: 1347-1352.

8. Transdermal Nicotine Study Group. Transdermal nicotine for smoking cessation: results of two multicenter controlled trials. JAMA 1991; 266: 8138-8188.

9. Dale LC, Hurt RD, Offord KP, Lawson GM, Croghan IT, Schroeder DR. High-dose nicotine patch therapy: percentage of replacement and smoking cessation. JAMA 1995; 274: 1353-1358.

10. Sachs DPL. The use and efficacy of nicotine patches. J Smoking Related Dis 1994; 5 (Suppl. 1): 183-193.

11. Sachs DPL, Benowitz NL, Bostrom AG, Hansen MD. Linearity of serum nicotine concentration and success of nicotine patch therapy in tobacco dependency treatment. In: Harris LS, ed: Problems of Drug Dependence, 1995. Proceedings of the 57th Annual Scientific Meeting, The College on Problems of Drug Dependence, Inc. Volume II. NIDA Research Monograph. Washington, DC, US Department of Health and Human Service, 1996; (in press).

12. Hughes JR. Treatment of nicotine dependence. Is more better? JAMA 1995; 274: 1390-1391. 